\title{
An Enterprise Management Framework for Costs Engineering Estimation Models Based on Scopus Scientometrics. An Aerospace Engineering Case Study
}

\author{
T. V. Aksenova ${ }^{1, *}$ \\ ${ }^{1}$ Ural Federal University named after the first President of Russia B. N. Yeltsin, 620002, 19 Mira \\ street, Ekaterinburg, Russian Federation
}

\begin{abstract}
The cutting-edge industrial product creation faces battling goals. There is an additional expenditure need to enhance new product reliability, and nevertheless, an enterprise should reduce product costs to receive the long-term development funds. This conflict resolution depends on a design engineer, who should take into account the future product costs as early, as possible. So, the purpose of this article is to elicit the most widespread cost estimation models at all design stages. I purposely investigate the models' limits to propose their common frame. The research methodology is Scopus scientometrics. First, I elicit the most authoritative reviews on the design cost estimation topic. Then I made the reviews content analysis and summarize the models' limitations. Findings show that the design cost estimation models significantly vary. They do not eliminate or substitute for each other. Each model is suitable in an appropriate designing process place. Scientometric analysis points that advanced cost estimation models are poorly evolved for enterprise efficiency prediction including the aerospace industry. To overcome these obstacles, I propose an enterprise goal model. This study's novelty is that a fitting combination of cost estimation models ensures the whole enterprise's economical effectiveness.
\end{abstract}

\section{Introduction}

The successful full-scale advancement of high-technology production needs simultaneously both cost-reducing and product safety-enhancing. There always is an immeasurable variety of engineering alternatives. Computational modeling is continually evolving. Despite this, there are still essential calls for guidance and provision engineers for making feasible and evaluated cost-effective design choices [1]. An important question is whether a design engineer can be ruled to devise a profitable product. The designer develops alternative solutions, which allows a product to work with predetermined technical-operational parameters. But cost figures and manufacturing indicators are beyond his competency area. Economic effectiveness can be accurately estimated far more lately, after layouts creation

\footnotetext{
${ }^{*}$ Corresponding author: t.v.aksenova@urfu.ru
} 
and production launch. The elaborate computer systems for enterprise resources management cannot eliminate the time gap between the design engineering stage and the manufacturing stage effectiveness evaluation [2]. Similar questions exist not only while product designing but at every life-cycle product stage. All attempts to preliminarily organize the production activities events according to the "cause and effect" scheme inalterably fail. Extremely diversified and changeable preproduction events nonlinearly intersect and overlap. Computer control systems that have been developed with no specified purpose follow the principle "the higher the different control indicators number, the better". A consequence is that the number of quantifiable inconsistent management characteristics has exceeded any specialist's perception limit. The computer management control systems only intensify the specialists' dissatisfaction and disunity feelings [3]. The universal design process does not maintain a designer to have a way to the total process information.

This problem urges this study's object, which is to elicit the most widespread cost estimation models at both early paradigmatic design [12] and design pre-production stages. I purposely investigate their limits to propose a common frame. The field of the study is a publications array on the theme. The publication yardsticks are the Scopus database scientometrics.

\section{Method}

The Scopus scientometric database offers a wide range of evaluation techniques, such as publications grouping by scientific topics, their citation dynamics, cataloging publications by type - reviews, full-text articles, conference papers. An important article authority indicator is its citation number in subsequent articles. Scopus is a multi-disciplinary database. Therefore, to provide a representative publications array on a choosing scientific field, it is necessary to use both traditional and specific bibliometric tools. [4, p. 201].

The scientometric analysis algorithm is shown in figure 1.

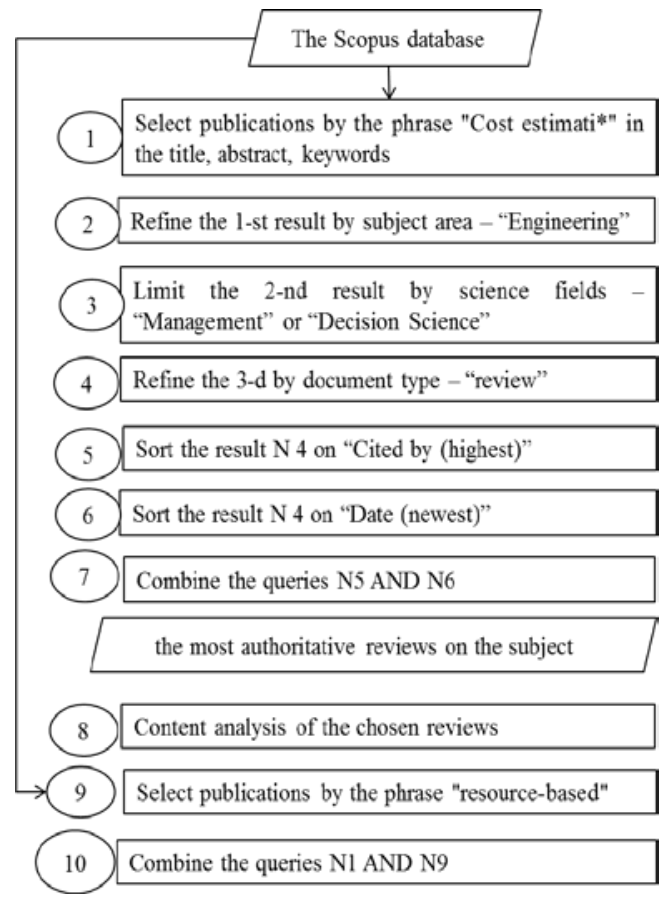

Fig. 1. The Scopus scientometric analysis algorithm. Source: author's elaboration 
First, I formed an array of publications on the topic "cost estimation" in the engineering sciences field. Then I specified the result for the management and decision-making purposes. From the resulting array, I selected the most authoritative reviews. The reviewer's authority measure is a twofold criterion:

$$
\left\{\begin{array}{c}
\text { Date of a review publication - the most recent; } \\
\text { The review citation index - the highest }
\end{array}\right.
$$

Then I provided a content analysis of the most authoritative reviews and pinpointed the most widespread cost evaluation technics at the designing stage. Finally, I investigated the cost estimation and enterprise resource management themes' mutual relationship.

\section{Results}

\subsection{The results of the scientometric analysis}

According to the evaluation criterion (1), the most complete and recent reviews on the topic are shown in table 1.

Table 1. Scientometrics of the Cost Estimation model subject reviews.

\begin{tabular}{clcc}
\hline $\mathrm{N}$ & & Publication year & Citation index \\
\hline 1 & Curran et al. & 2004 & 283 \\
2 & Niazi et al. & 2006 & 165 \\
3 & Hueber et al. & 2016 & 27 \\
\hline
\end{tabular}

The first review Curran et al. [5] establishes the evolution of the methods -classical and advanced estimating techniques (figure 2).

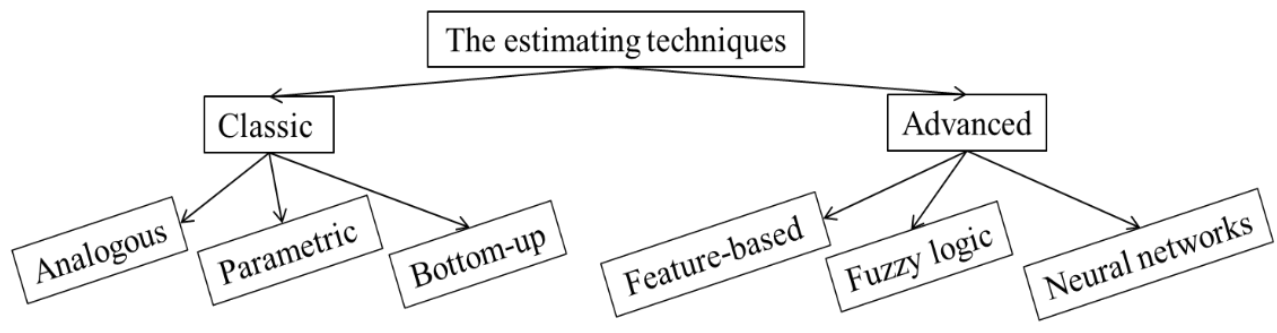

Fig. 2. State-of-the-art: cost estimating. Source: Curran et al., 2004

The classic models are listed as follows. One of the best-established and applied methods is analogous costing [5, p. 504]. It consists of adjusting the cost of a product pertinent to a target product taking into account differences between them. The method is effectively used within aerospace costing procedures [6].

The second classic method is parametric cost estimating. The presumption is that there are cost-driving product parameters observed to change as cost changes. A core procedure is a linear regression method, which highlights a relationship between cost as the dependent variable and the cost-driving parameters as independent variables based on historical enterprise data. This model is nowadays widespread in the Defense Industry [6].

One more classic method is bottom-up cost evaluation, which is used within the software and instrument-building industries [7]. An engineer should identify product components and make calculations, which include even the smallest details, to aggregate 
them to the overall product. The more detailed material, equipment, and labor data are the more precise cost figures one can finally obtain.

Hueber et al. [8] analyzed the classical methods' limitations and common features. The weakness of all classical models is that the choice of the design option depends entirely on the engineer and is not subject to technological and managerial control [8]. Additionally, neither classic model includes industrial specificity. Openly available industrial data are either sparse or have sustained serious abstraction. For example, there are data available from some US military aircraft and NASA programs, but these data cannot be applied for civil aircraft and airframe demands. In the civic industries, an engineer should pay the most attention to the factors, such as design modules availability, manufacturability, batch production requirements which are enterprise-specific and inimitable [6], [7].

Curran et al. [5] argue that the product parameters' change uncertainty is intrinsic for the aerospace industry. That is why it is appropriate to use advanced estimating cost techniques. The first of them is feature-based modeling. The presumption is that costs allocate to each separate product feature accordingly. The model divides a whole product cost into short costs assigned to the product design architecture: individual design features; a component assembly level; an order or batch level. This structure can be rigorously applied to the classes of similar products, provided that the model ignores components' interrelationships. This model is adequate only for the consequential manufacturing process as far as it cannot include the factor of exogenous environment turbulence [7].

Another advanced approach is fuzzy logic cost modeling. It addresses a heterogeneous product characteristics multitude, which relationships are nebulous. Fuzzy logic modeling consists of continuous assignment functions instead of the sharp-edged traditional cost estimation models. A modeling result is a set of rules that indicate the relationships between the vague and imprecise input variables and output cost evaluation [7]. The model can be used for automated analogous estimations and in computational systems in the defense and aerospace industries [2].

Finally, Curran et al. [5] analyzed the neural networks (further mentioned as NN) that allow an engineer to cope with large-scale data. The neural network models consist of a large number of data units (the neurons) linked via weighted connections. A model reacts to inputs by performing the entirety of the weighted neurons' impulses. The result initiates one or more specific output neurons that intend to be the net's answer. The model repeatedly links input data and learns itself. However, the method does not simplify an engineer's decision-making. The engineer needs to: 1) define the problem domain; 2) list apparent cost drivers; 3) supply the relevant cost data; 4) qualify data' importance. Consequently, the neural model, being of an ad hoc nature, undermines the other enterprise specialists' trust.

\subsection{The NN method scientometrics for the aerospace industry management}

The initial presume is that the scientific article number reflects the science development depth. A short Scopus analysis shows the NN method spreading for aerospace management (table 2). 
Table 2. The scientometrics of the aerospace industry's NN estimating cost methods. The management viewpoint

\begin{tabular}{|c|c|c|c|c|}
\hline \multirow[t]{2}{*}{ № } & \multirow[t]{2}{*}{ Search purpose } & \multirow[t]{2}{*}{ Search query } & \multicolumn{2}{|c|}{$\begin{array}{c}\text { Document } \\
\text { number }\end{array}$} \\
\hline & & & $\begin{array}{c}\text { Numbe } \\
\mathrm{r}\end{array}$ & $\%$ \\
\hline 1 & $\begin{array}{l}\text { NN cost estimation } \\
\text { methods application } \\
\text { for management in } \\
\text { all industries }\end{array}$ & $\begin{array}{llll}\text { (TITLE-ABS-KEY } & \text { ("Neural } & \text { networks") } & \text { AND } \\
\text { TITLE-ABS-KEY } & \left(\text { cost*)) }^{*} \text { AND }\right. & \text { (LIMIT-TO } \\
\text { (SUBJAREA, "DECI") } & \text { OR } & \text { LIMIT-TO } \\
\text { (SUBJAREA, "BUSI")) } & & \\
\end{array}$ & 2,190 & 100 \\
\hline 2 & $\begin{array}{l}\text { Refine results № } 1 \\
\text { considering the } \\
\text { aerospace specifics }\end{array}$ & $\begin{array}{l}\text { (TITLE-ABS-KEY ("Neural networks") AND } \\
\text { TITLE-ABS-KEY (cost*) AND TITLE-ABS- } \\
\text { KEY (aerospace)) }\end{array}$ & 164 & 7,5 \\
\hline 3 & $\begin{array}{l}\text { Refine results № } 2 \\
\text { for } \quad \text { management } \\
\text { decision making }\end{array}$ & $\begin{array}{llrr}\text { (TITLE-ABS-KEY } & \text { ("Neural networks") } & \text { AND } \\
\text { TITLE-ABS-KEY (cost*) } & \text { AND } & \text { TITLE-ABS- } \\
\text { KEY (aerospace)) AND } & \text { (LIMIT-TO } \\
\text { (SUBJAREA, "DECI") } & \text { OR } & \text { LIMIT-TO } \\
\text { (SUBJAREA, "BUSI")) } & & \end{array}$ & 8 & 0,4 \\
\hline
\end{tabular}

Source: author's elaboration

The publications number in the search $\mathrm{N} 2$, which reflects the use of $\mathrm{NN}$ for the aerospace industry economics consists of $7,5 \%$ of the total topic publications number (search $\mathrm{N} \mathrm{2,} \mathrm{table} \mathrm{2).} \mathrm{That} \mathrm{is} \mathrm{a} \mathrm{modest} \mathrm{figure} \mathrm{comparing} \mathrm{with,} \mathrm{for} \mathrm{example,} \mathrm{the} \mathrm{construction}$ industry or the financial sector for shares value assessing $-22,0 \%$ and $21,7 \%$ respectively.

The refined 2-nd search content analysis shows that NN methods in the aerospace industry have been developing toward solving specific technical problems such as computing costs, the cost of training [9], reducing the satellite imagery cost [10]. Zhou et al. [9] examined deep convolutional NN models for blending engineering hallmarks to realize the automatic feature extraction from large-scale data. De Cos et al. [11] studied the application of cost estimation methods for predicting the aerospace industry turbine manufacturing costs case study.

The search N 3 confirms that NN cost estimation methods are poorly developed for the aerospace industry's management efficiency. NN publications number (line 3, table 2) consists of $0.4 \%$ of the amount of the subject publication (the 1-st search).

That is the reason to couple fussy logic and NN models in one class further named in this article as FLNN modeling.

\subsection{An engineering cost estimation models' junction}

Both classical models and advanced ones' common drawback is that they allow an engineer to estimate only the separate or analogous products' costs. Still, provided that the enterprise's external environment varies paradigmatically and unpredictably, then the aerospace and defense enterprises struggle the challenge of resources set reconfiguration as a whole [12]. That is why all the above-mentioned cost estimation models should serve an enterprise additionally to face the problem of asset combinations as an entity.

FLNN modeling empowers to prove and measure the tacit factors' change probability. That is why we can apply an FLNN model to enlist the long-term paradigmatic R\&D initiatives [12]. But these models do not enable us to solve the enterprise resource composition problem, so we need to apply them as a part of a management toolkit only.

The enterprise as an integral set of resources is the resource-based theory's object. The scientometric analysis conducted at the 9-th algorithm's step showed that there only 11 
publications are at the intersection of the cost estimation and resource-based theory subjects. Content analysis of these articles showed the following.

1. To control the entire set of specialized resources one needs to combine advanced estimating models with the traditional ones [13].

2. The evaluation of the operational costs should be source-specific [14]. These estimates should be linked with heterogeneous cost data to make resource-based estimates [13].

3. A flexible cost estimation method combination can only be feasible in the case of an enterprise goal orientation [14].

4. To ensure effective design preproduction and manage long-term resources at the same time, it is necessary to allocate a pre-design conceptual phase in the full R\&D cycle [12], [14].

The design preference in all classical cost estimation models depends on an engineer entirely [8]. To avoid this vulnerability, it is necessary:

1) to organize the different specialists' knowledge exchange; all organizational structure units should take parts in design options making;

2) to verify design cost estimation results with a whole enterprise management goal.

As far as the aerospace industry poses substantial difficulties for the financiers [5], so we should connect different R\&D stages, estimating models, and financial sources respectively.

The concept that integrates all the above-listed evaluation models' usage is shown in figure 3 .

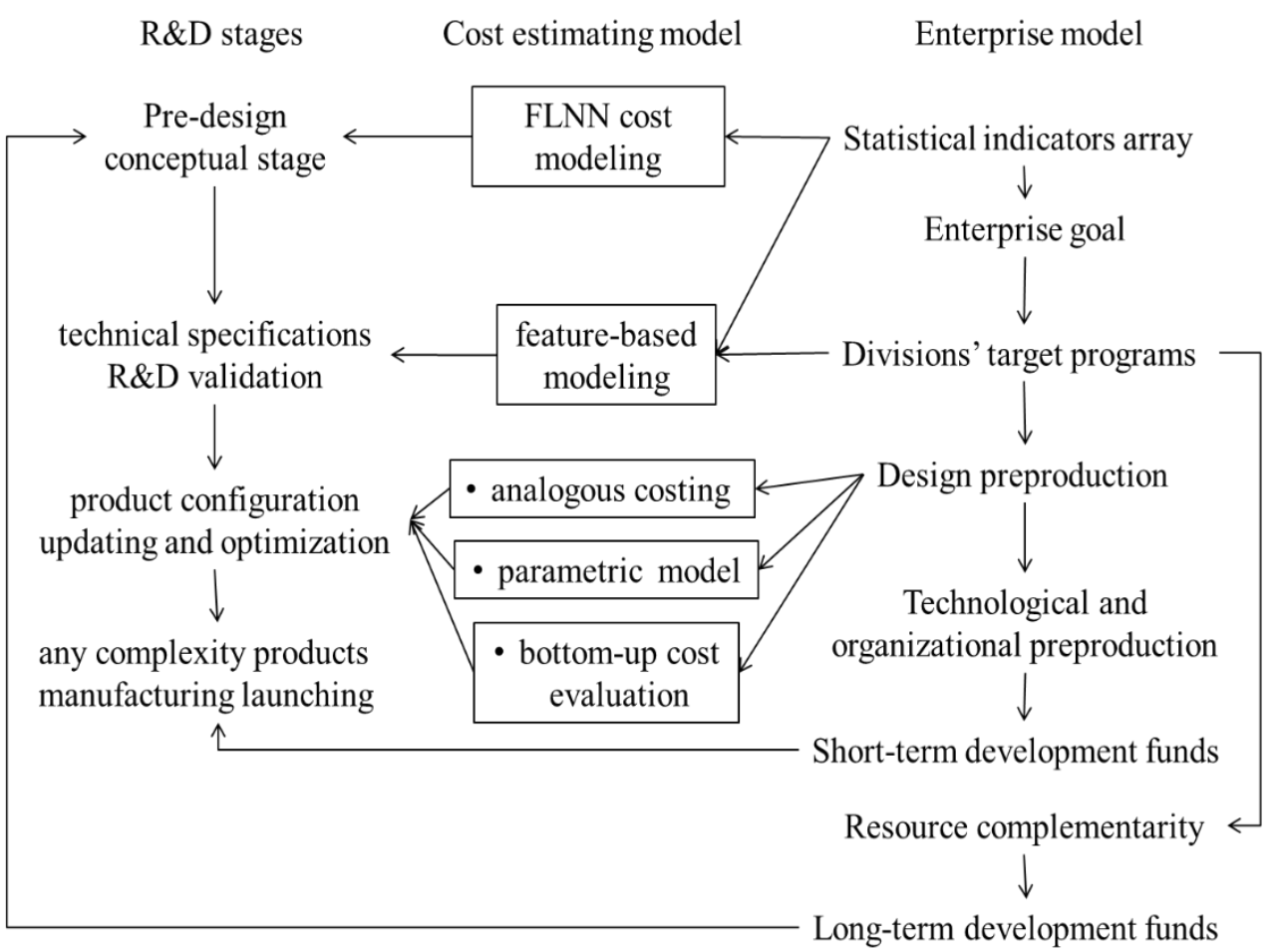

Fig. 3. The Engineering Costs Estimation Models Framework. Source: author's elaboration

We should highlight the pre-design paradigmatic stage in an R\&D cycle [12]. Despite that there is no cost-effective product creation at this design stage [12], it determines the organization's scientific and technical potential. Therefore, this R\&D stage determines 
enterprise sustainability on the enterprise goal level of importance. An FLNN model application is the most appropriate here, regarding unforeseen and paradigmatic technological confusions in the enterprise external environment.

Furthermore, as far as an FLNN model appears to be of "a black box" nature [5], so the model's solutions often seem illogical for the other enterprise specialists. I suggest the models should be applied for long-term engineer groundwork at the pre-design paradigmatic $\mathrm{R} \& \mathrm{D}$ stage.

As far as the feature-based design modeling is consistent only with a consequential technological process, where a gauge of manufacturability affects the cost directly [7], we can apply the model for:

1) the longstanding products' local improvements;

2) the straightforward designing tasks that do not affect technical contradictions.

All classic estimating methods suffer shortcomings of industrial specificity [8]. That is why we should build the classical estimating models on path-dependent enterprise data assemblages. Elmousalami [1] argues that these methods are weak to generate valid results for conceptual cost prediction due to the meager and enterprise dataset. I argue that the lively internal interaction of specialists, when coordinating the targeted programs, compensates this shortcoming. The new information fills in the enterprise database blank spots.

The divisions' target programs coordinating procedure puts each cost estimating model in the proper places for both the long-term paradigmatic design phase and the shifty design preproduction.

\section{Conclusions}

Scientometrics allows us to identify the topic reviews that meet the complex criterion of novelty and authority. The analysis of these reviews allows us not so much to characterize the various methods of cost estimation but to analyze the whole set of their limitations. The classical cost estimation methods, which are more user-friendly, are crisp and deterministic [7]. To face the unforeseen external requirements, they give a significant error in the longtime cost estimating. Advanced methods are expensive and time-computer consuming. That impedes the search for optimal designs for short-term product customization.

All above-mentioned model decisions are sensitive to ad hoc design engineer skills. But in reality, the implicit choices are buried in many features of organizational forms and customs. Put differently, selecting the right product architecture requires not just understanding the choices available but assembling the heterogeneous capabilities of all organizational structure units [12].

Up-to-date research, which combines cost estimation methods, recommends hybrid models based on a fuzzy logic basis [1]. The research confronts them to other machine learning algorithms to select the most accurate one. But this research is for construction projects.

I propose another approach. The matter is that the industrial enterprises, especially science-driven ones, have the peculiarity that the cost estimation modeling should not be focused on product updating itself. If an enterprise enters into a market with new and superior products then the enterprise assets value will reduce promptly because of installed and under-amortized equipment and inventory [12]. That is why any cost estimating should be aimed at the enterprise whole efficiency. The issue is not about "which of the cost estimation models is the most excellent?" but rather "when it is relevant?" [8]. An answer presumably lies within the enterprise heterogeneous divisions' interaction framework. 


\section{References}

1. Elmousalami HH 2021. Comparison of Artificial Intelligence Techniques for Project Conceptual Cost Prediction: A Case Study and Comparative Analysis. IEEE Trans Eng Manage 68 183-196.

2. He X, Liu R and Anumba CJ 2021. Data-Driven Insights on the Knowledge Gaps of Conceptual Cost Estimation Modeling J Constr Eng Manag 147.

3. Cyert R and March J 2015 Behavioral theory of the firm Organizational Behavior 2: Essential Theories of Process and Structure ed. Eugene (United States) pp 60-77.

4. Gaviria-Marin M, Merigó JM and Baier-Fuentes H 2019. Knowledge management: A global examination based on bibliometric analysis Technol Forecast Soc Change $\mathbf{1 4 0}$ 194-220.

5. Curran R, Raghunathan S and Price M 2004. Review of aerospace engineering cost modelling: The genetic causal approach Prog Aerosp Sci 40 487-534.

6. Post DE, Eslinger OJ, Sundt SM and Holland M 2019. CREATE/ERS: Department of Defense acquisition reform through resilient engineering and virtual prototyping in a digital environment $J$ Def Model Simul 16 357-371.

7. Niazi A, Dai J S, Balabani S and Seneviratne L 2006. Product cost estimation: Technique classification and methodology review J Manuf Sci Eng Trans ASME 128 563-575.

8. Hueber C, Horejsi K, and Schledjewski R 2016. Review of cost estimation: methods and models for aerospace composite manufacturing Adv Manuf Polym Compos Sci 2 $1-13$.

9. Zhou Z, Li T, Zhao Z, Sun C, Yan R and Chen X 2020. Differentiable Architecture Search for Aeroengine Bevel Gear Fault Diagnosis International Conference on Sensing Measurement and Data Analytics in the Era of Artificial Intelligence, ICSMD 2020.

10. Kumar Nayak G, Jain S, Venkatesh Babu R and Chakraborty A 2020. Fusion of Deep and Non-Deep Methods for Fast Super-Resolution of Satellite Images Proceedings 2020 IEEE 6th International Conference on Multimedia Big Data, BigMM.

11. de Cos J, Sanchez F, Ortega F and Montequin V 2008. Rapid cost estimation of metallic components for the aerospace industry Int J Prod Econ 112 470-482.

12. Teece D J 2019. A capability theory of the firm: An economics and (strategic) management perspective. New Zealand Economic Papers 53 1-43.

13. DeSoto BGD and Adey BT 2016. Preliminary resource-based estimates combining artificial intelligence approaches and traditional techniques Paper presented at the Procedia Engineering 164 261-268.

14. Schuh G, Prote J and Schmitz T 2017. Resource-based cost modeling - A new perspective on evaluating global production networks Paper presented at the Procedia CIRP 63 64-69. 